\title{
Efficiency of Mycorrhizal Fungi with Different Levels of Phosphatic Fertilizer on Growth of Piper mullesua Plantlets
}

\author{
Arundhati Bordoloi ${ }^{1^{*}}$ and A. K. Shukla ${ }^{2}$ \\ ${ }^{1}$ Krishi Vigyan Kendra, Sivasagar, Assam Agricultural University \\ ${ }^{2}$ Indira Gandhi National Tribal University, Amarkantak, MP, India \\ *Corresponding author
}

\section{Keywords}

Mycorrhizal fungi, Super phosphate, Piper mullesua, Plant biomass and phosphatase

Article Info

Accepted:

05 February 2020 Available Online: 10 March 2020
A B S T R A C T

A greenhouse experiment was carried out to study the efficiency of Arbuscular Mycorrhizal fungi indigenous to Arunachal Pradesh in uptaking plant nutrients for the Piper mullesua plantlets at different levels of phosphatic fertilizer (Single Super Phosphate). In plants, $\mathrm{P}$ availability is considered the second most important limiting factor for growth after nitrogen. While $\mathrm{P}$ is generally abundant in soil, it is mostly present in insoluble and poorly mobile forms and therefore partly unavailable to plants. Mycorrhiza develop a dense hyphal network that extends far into the soil while still remaining connected to the root. This extraradical mycelium provides the plant with water and nutrients especially phosphorous that would otherwise remain inaccessible to roots. In the present study, Piper mullesua seedlings were infected with ten different strains of AM fungi and one without inoculation of AM fungi under three levels of phosphatic fertilizer (superphosphate). Shoot length, plant biomass, phosphatase enzyme activity, concentration of $\mathrm{P}$ and $\mathrm{N}$ of $\mathrm{AM}$ infected plants were found higher than those of non-mycorrhizal controls, which confirms the contribution of AM fungi. In our experiment it has been found that mycorrhizal fungal isolates $G$. etinucatum $(0.887 \mathrm{gm} \pm 0.033)$, G. claroidium $(0.861 \mathrm{gm} \pm 0.023)$ and $G$. aggregatum $(0.859 \mathrm{gm}$ $\pm 0.016)$ performed significantly $(p>0.001, \mathrm{~F}=14.14)$ higher in improving plant biomass of Piper mullesua seedlings at lower dose of super phosphate which confirms higher efficiency of mycorrhizal fungi with reduced dose of phosphatic fertilizer.

\section{Introduction}

Piper mullesua D. Don. (syn $P$. brachystachyum Wall ex Hook. f), an important medicinal plant belonging to the family Piperaceae. It is commonly known as Pipli, Pahari peepal, is indigenous to Arunachal Pradesh (India) and widely distributed in the Eastern Himalayan region at an altitude of about $600 \mathrm{~m}$ to $1500 \mathrm{~m}$. Male and 
female flowers are found in separate spikes of the plant. Male spikes are 3-6 cm long, erect, slender and cylindrical. Female spikes are globose, oblong erect. Roots and fruiting spikes are used in treating diarrhea, indigestion, jaundice, urticacia, abdominal disorder, horseness of voice, asthma, cough, piles, malaria fever, vomiting wheezing, chest conjestion, throat infection, worms and sinusitis. Piper mullesua is also considered as a rejuvenating plant. Myristicin, a 1,3benzodioxole has been extracted from the hexane fraction of alcohol extract of fruit bearing inflorescence of Piper mullesua which has insecticidal properties (Srivastva et al., 2001).

Phosphorus $(\mathrm{P})$ is one of the most important determinants of plant growth and in most soils it exists in forms that are largely unavailable for plant uptake (Zafar et al., 2011). Phosphorus (P) serves various basic cellular functions in bioenergetics. $\mathrm{P}$ is the key player in plant metabolic processes, including energy transfer, signal transduction, biosynthesis of macromalecules, photosynthesis and respiration (Raghothama, 1999; Mengel and Kirkby, 2001). In plants, $P$ availability is considered the second most important limiting factor for growth after nitrogen. While $\mathrm{P}$ is generally abundant in soil, it is mostly present in insoluble and poorly mobile forms and therefore partly unavailable to plants (Schachtman et al., 1998). Like all other mineral nutrients, $\mathrm{P}$ enters the biosphere predominantly via the pedosphere through the root system of plants, where it is absorbed as inorganic orthophosphate (Pi), which is preferred form taken up by plants (Bucher, 2006). Phosphorus that exist in the environment as $\mathrm{Pi}$, primarily evolved in inert complexes with cations such as iron phosphate $\left(\mathrm{FePO}_{4}\right)$ and aluminium phosphate $\left(\mathrm{AlPO}_{4}\right)$, and in organic molecules such as lecithin and phytate, the latter of which can account for up to $50 \%$ of total soil organic Pi
(Brinch-Pedersen et al., 2002). Roots take up $\mathrm{P}$ as inorganic phosphate $(\mathrm{Pi})$, and this leads to the creation of Pi depletion zones around them, a phenomenon that can lead to $\mathrm{P}$ deprivation. Crop plants are thus commonly supplied with chemical $\mathrm{P}$ fertilizers, which raises several major economic and environmental concerns related to energy use, freshwater pollution and mineral $\mathrm{P}$ resource scarcity (Cordell et al., 2009; Gilbert, 2009).

Arbuscular mycorrhizal symbioses are arguably the most common underground symbiosis, with around $80 \%$ of terrestrial plant species (Smith and Read, 2008), forming the most widespread symbiosis on earth (Brachmann and Parniske, 2006). In this root endosymbiosis, the fungal partner colonizes the root cortex where it forms specialized structures called arbuscules that serve as an exchange interface. At the same time, the fungus develops a dense hyphal network that extends far into the soil while still remaining connected to the root. This extraradical mycelium provides the plant with water and nutrients that would otherwise remain inaccessible to roots. Among supplied nutrients, $\mathrm{Pi}$ is considered as quantitatively the most important (Smith and Read, 2008). AM fungi can obtain free $\mathrm{Pi}$ from the soil using high-affinity $\mathrm{Pi}$ transporters expressed in the mycelium (Harrison and van Buuren, 1995). Once taken up by the extraradical mycelium, $\mathrm{P}$ is translocated along the hyphae in the form of polyphosphates, which are then depolymerized so that Pi can be transferred to root cells in exchange for hexoses (Ohtomo and Saito, 2005). On the other hand, organic phosphorus in soil is made available to plants largely after its mineralization or when hydrolyzed into Pi. Mineralization and hydrolysis of Po is mediated by the enzymatic activity of phosphatase. AMF roots have greater enzymatic acid phosphatase (ACP) and alkaline phosphatase (ALP) activity compared to non AMF roots. It has been 
demonstrated that plants can receive up to $100 \%$ of their $\mathrm{P}$ via the mycorrhizal pathway, and from 4 to $20 \%$ of plant carbon can be transferred to the fungi (Cavagnaro, 2008). Considering the higher efficiency of mycorrhizal fungi in uptaking phosphate from soil, now days, application of AMF as a biofertilizers in crop production is recommended with aim of increasing productivity and reducing use of chemical fertilizers which are expensive, produce short term benefits and above all their use may create environmental pollution (Prasad et al., 2012 and Kumar et al., 2019).

Thus, the aim of the present study was to investigate how the AM symbiosis is effective in nutrient acquisition from soil at different levels of phosphatic fertilizer (Single Super Phosphate) for the growth of Piper mullesua plantlets under greenhouse condition.

\section{Materials and Methods}

The study was carried out in and around Doimukh area of Papum Pare district and Pasighat area of East Siang District of Arunachal Pradesh $\left(26^{\circ} 30^{\prime}\right.$ N-29 ${ }^{\circ} 30^{\prime} \quad \mathrm{N}$ Latitude and $91^{\circ} 30^{\prime} \mathrm{E}-97^{\circ} 30^{\prime} \mathrm{E}$ Longitude; altitude 100-600m asl). The region experiences a humid tropical climate (Rainfall $110-160 \mathrm{~cm}$; annual temperature $12^{\circ} \mathrm{C}-37$ $\left.{ }^{\circ} \mathrm{C}\right)$. The vegetation type corresponds to tropical semi-evergreen forest. The soil texture of area ranges from sandy loam to loamy sand and $\mathrm{pH}$ ranges from 4.9-6.7. Plantlets of piper were raised through stem cuttings. The plantlets were raised in sterilized sand and soil mixture (3:1). Soil samples were collected from different locations in Arunachal Pradesh for isolation of VAM fungal spores. Samples were taken from depth of $0-15 \mathrm{~cm}$ under various land use systems such as forest area, jhum fields, home gardens as well as natural habitat of piper plants. Mycorrhizal fungal spores were isolated from soil by the method as suggested by Gerdmann and Nicholson (1963). Ten AM fungal species i.e., $G$. etunicatum, $G$. versiforme, $G$. albidum, $G$. claroidium, G.occulatum, G. macrocarpum, G. hoi, G. aggregatum, G. fasciculatum, G. aurantium were selected to carry out the experiment.

A pot experiment was carried out with 11 treatments viz., non-mycorrhizal $P$. mullesua plantlets as control. Recommended dose of commercial phosphatic fertilizer for piper is $250 \mathrm{~kg}$ single superphosphate (SSP) per ha. For this experiment we selected 3 treatments on the basis of recommended dose i.e. half, full and double of recommended dose. In treatment I, $0.089 \mathrm{gm}$ of SSP was mixed with $200 \mathrm{gm}$ of sterilized 3:1 sand and soil mixture and one seedling of piper plant was planted. Same treatment was given to each of the 3 replicates. In treatment II $(100 \%), 0.1776 \mathrm{gm}$ of SSP was mixed with $200 \mathrm{gm}$ sterilized $3: 1$ sand and soil mixture. Same technique was followed in treatment III. Here the P fertilizer was taken $0.3552 \mathrm{gm}$ for each pot. 3 replicates were taken for each treatment. One set of control was also kept for comparison of data. Pots were kept in mist chamber and harvesting was done after 90 days after transplanting.

Growth parameters like shoot and root length as well as plant biomass was determined by drying them separately in hot air oven at 60 ${ }^{\circ} \mathrm{C}$ for 48 hours. The percentage of the root colonized by VAM fungi were determined by using the formula as suggested by Brundreett et al., (1996). The chlorophyll content of leaf of $P$. mullesua was estimated by the method of Witham et al., (1971). The total nitrogen and phosphorus content of plant material was determined by the Kjehldahl method and Vanadomolybdate method respectively (Juo, 1982). The activity of Phosphatase was estimated by method suggested by Tabatabai and Bremner (1969). 
The data was subjected to one-way analysis of variance (ANOVA) to determine the effect of treatments. Correlation coefficient was calculated to evaluate the strength of the relationship of total plant biomass with the other parameters considered in the study.

\section{Results and Discussion}

\section{Shoot and root length}

In the present investigation, it was found that mycorrhizal inoculation with low level of superphosphate fertilizer increased shoot and root length of the plantlets as compared to the control. At low level of superphosphate, shoot length of Piper seedling was observed highest in the seedlings inoculated with $G$. claroidium $(8.83 \mathrm{~cm} \pm 0.35)$ and least in the seedlings inoculated with $G$. aurantium $(6.33 \mathrm{~cm} \pm 0.1)$ which was significantly higher $(p>0.01$, $\mathrm{F}=4.995)$ than the non-mycorrhizal seedlings $(5.63 \mathrm{~cm} \pm 0.25)$ (Table 1). Increased in shoot length might be due to the enhanced nutrient uptake and greater rate of photosynthesis by mycorrhiza inoculated with the plantlets. This supports the results of Cooper (1984), Allen et al., (1981) and Prasad et al., (2012). In case of root length, AM inoculated roots were ranged $40.67 \mathrm{~cm} \pm 0.48$ to $32.63 \pm 0.1$ as compared to the non-mycorrhiza control seedlings $(42.83 \mathrm{~cm} \pm 0.1)$. Zhang et al., (2019) also found mycorrhizal plants possessed better root hair growth as compared to the non mycorrhizal plants. It is evident from the table 1 that shoot length was found highest ( $p>0.001, \mathrm{~F}=7.697)$ in the seedlings of non-mycorrhizal control plants $(8.25 \mathrm{~cm}$ \pm 0.12 ) as compared to all AM inoculated seedlings under medium superphosphate and $8.22 \mathrm{~cm} \pm 0.09$ under high dose of superphosphate. Root length of the seedlings both inoculated and un-inoculated did not show any significant difference. Root length was highest in non-mycorrhizal plants $(46.83 \mathrm{~cm} \pm 2.36)$ and was least recorded in seedlings inoculated with $G$. etunicatum $(42 \mathrm{~cm} \pm 0.95)$.

Increased shoot and root length might be the result of enhanced inorganic nutrient uptake and and greater rate of photosynthesis. This results were supported by the findings of Tanwar et al., (2012), Cooper, 1984) and (Allen et al., (1981). The results are also in close conformity with Gaur et al., (2000) who found increase in vegetative growth of Petunia hybrida, Callistephus chinensis and Impatiens balsamina while inoculating with AM fungi and recommended dose of chemical fertilizers. El-Khateeb et al., (2010) also observed increase in height of Chamedora elegans by AM fungi and NPK. The effectiveness of lower concentration of superphosphate in increasing the root length may be due to the direct effect of superphosphate fertilizers or indirectly through the microbial propagation activation. AMF enhanced nutrient uptake by increasing surface area of roots with the development of an extensive extra- radical hyphae network (Smith and Read, 1997).

\section{Biomass}

Both AM colonization and $\mathrm{P}$ nutrition caused an increase in plant biomass as compared to the non-mycorrhizal control plants at low level of superphosphate, where half of the recommended dose of P-fertilizer was applied. This increase was evident at the lower $\mathrm{P}$ level of nutrition in AM colonizes plants, where fungal isolates $G$. etinucatum $(0.887 \mathrm{gm} \pm 0.033)$, G. claroidium $(0.861 \mathrm{gm}$ $\pm 0.023)$ and $G$. aggregatum $(0.859 \mathrm{gm}$ $\pm 0.016)$, performed significantly $(p>0.001$, $\mathrm{F}=14.14$ ) higher in improving plant biomass of Piper mullesua seedlings relative to control plants $(0.454 \mathrm{gm} \pm 0.02)$. At medium level of $\mathrm{P}$, same trend of performance of the fungal isolates as low level of $\mathrm{P}$ has been shown where plant biomass of Piper mullesua 
seedlings ranged between $0.553 \mathrm{gm} \pm 0.006$ to $549 \mathrm{gm} \pm 0.006$. At this level, non-mycorrhizal control seedlings produced significantly $(p>0.001, \mathrm{~F}=8.403)$ higher biomass $(0.530 \mathrm{gm}$ $\pm 0.034)$ as compared to some seedlings inoculated with AM fungi. At higher P level, Plant biomass produced by non-mycorrhizal control $P$. mullesua seedlings $(0.541 \mathrm{gm}$ $\pm 0.001)$ was significantly $(\mathrm{p}>0.001, \mathrm{~F}=15.16)$ higher than the AM inoculated plants and least biomass was produced by $G$. aurantium $(0.414 \mathrm{gm} \pm 0.003)$ (Figure 1).

Mycorrhizal inoculation increased plant biomass in the plants compared to the nonmycorrhizal control plants at low and medium level of $\mathrm{P}$, supports the results of Subramanian et al., (2008) suggested that the growth enhancement in AM fungusinoculated plants may be associated with the availability of soil nutrients. This shows that the recommended fertilizer dose can be reduced in combination with efficient mycorrhizal strain. This finding is in line with Cebalos et al., (2013), Aliyu et al., (2019) and Singh et al., (2019). Higher concentration of phosphatic fertilizer markedly reduced plant biomass as compared to medium and low concentration of phosphatic fertilizer. Prasad et al., (2012), noted similar findings while studying the impact of different levels of superphosphate on mycorrhizal fungi. Reduced biomass at higher level of $\mathrm{P}$ might be due to lesser efficiency of mycorrhizal fungi in presence of sufficient amount of water soluble phosphorus.

\section{Chlorophyll content}

Low concentration of superphosphate was found to be more effective in high chlorophyll content. Inoculation with $G$. claroidium and low level of superphosphate significantly increased the chlorophyll content of the Piper mullesua plantlets $(1.902 \mathrm{mg} / \mathrm{gm} \pm 0.02)$ which was significantly $(p>0.005, F=3.442)$ higher than the non-mycorrhizal control plants. Similar result was found in medium level of superphosphate which was significantly ( $>00.005, \quad \mathrm{~F}=3.442)$ higher in $G$. macrocarpum $(1.802 \mathrm{mg} / \mathrm{gm} \pm 0.009)$ than the non-mycorrhizal control plants. At high superphosphorus level, non mycorrizal control plants showed highest chlorophyll content which was not significant (Table 2).

It is seen that higher dose of phosphatic fertilizer does not play an important role in enhancement of chlorophyll and ultimately the photosynthesis process in mycorrhizal inoculated plantlets. But in the mycorrhizal plantlets when applied with low dose of recommended dose and recommended superphosphate showed very good relation with mycorrhizal infection and total chlorophyll content. Increased chlorophyll content on inoculation with mycorrhizal fungi was also reported by Tanwar et al., (2013).

\section{Percent infection}

After 90 days of inoculation, percent mycorrhizal root colonization increased in all the treated plantlets over the control (Table 2). maximum percent root colonization was present in the plantlets inoculated with $G$. macrocarpum $(73.33 \% \pm 6.94)$ at low level of $\mathrm{P}$ and least in the plantlets at higher $\mathrm{P}$ level inoculated with $G$. aurantium $(6.7 \% \pm 1.9)$. From the results, it has been found that $G$. macrocarpum not only performed best in lower $\mathrm{P}$ level, it also produced better infection in medium $P$ level $(36.65 \pm 5.09)$ and also in higher P level (18.3 \pm 4.2$)$ where $G$. versiforme $(20 \% \pm 3.3)$ produced highest infection (Table $2)$. In our experiment it has been found that percent infection in the plantlets at medium level of $\mathrm{P}$ was lesser than the infection produced by same strain at lower level of $\mathrm{P}$ fertilizer. It was found least in presence of higher level of phosphatic fertilizer.

Lower concentration (half of the 
recommended dose of $\mathrm{P}$ fertilizer) showed better results than recommended and double of recommended dose. It may be high soil phosphate level determines the reduction of hyphal growth of mycorrhizal fungi. Results are in accordance of Guillemin et al., (1985), Linderman and Davis (2004), Prasad et al., (2012) and Tiamtanong et al., (2014). Balzergue et al., (2013), supports these findings explaining that a high level of $\mathrm{P}$ fertilization inhibits AM symbiosis predominantly by acting on the plant itself rather than on the content of its root exudates or on the fungal partner. Aliyu et al., (2019) also reported that colonization of the cassava roots by $\mathrm{AMF}$ decreased with increasing $\mathrm{P}$ application.

\section{Survivality}

Effect of mycorrhizal fungi on survivility of inoculated mycorrhizal fungi was contrasting. The percent survivality in P level I was found in the seedlings inoculated with AM fungi G. claroidium (90\%) and least survivality was found in the non-mycorrhizal seedlings. In case of $\mathrm{P}$ level-II, highest survivality was observed in case of non-mycorrhizal seedling (80\%). At P level III, highest survivality was found in non-mycorrhizal $P$. mullesua seedlings (Table 2.1). This parameter did not show any stimulatory effect on mycorrizal plantlets at different level of superphosphate (Table 2).

\section{Phosphatase content of roots}

After 90 days of inoculation, maximum phosphatase activity was observed in the plantlets at low level of $\mathrm{P}$ inoculated with $\mathrm{AM}$ fungi G. claroidium $(27.28 \mu \mathrm{g} / \mathrm{gm} \pm 0.192)$, where half of recommended dose of phosphatic fertilizer were used. In this experiment Phosphorus content of root was always significantly $(p>0.001, \quad \mathrm{~F}=14.83)$ higher than the control plants. The activity of phosphatase also followed the same pattern in medium level of $\mathrm{P}$ as plantlets inoculated with G. claroidium $(23.77 \mu \mathrm{g} / \mathrm{gm} \quad \pm 0.504)$, followed by $G$. etunicatum $(23.490 \mu \mathrm{g} / \mathrm{gm}$ \pm 1.285 ). However higher concentration of $\mathrm{P}$ did not show any significant result (Figure 2).

Measurement of the phosphatase activity provided a good index of mycorrhizal effect on nutrient uptake, especially phosphorus. The ability of mycorrhizae to produce phosphatase enzymes actually depends upon the availability of phosphorus in the soil. In the $\mathrm{P}$ cycle, enzyme activities are inversely related to $\mathrm{P}$ availability (Tadano et al., 1993) which also supports the findings that decrease the available phosphate cause an overall increase in the phosphatase activity (Azcón and Barea, 1997). Tiamtanong et al., (2015) concluded that at low phosphorus availability, $\mathrm{P}$ demand increases that resulting increase the phosphatase activity which supports our results. High soil superphosphate concentration resulted in the reduction of hyphal growth and spore production of arbuscular mycorrhizal fungi that ultimately reduced the phosphatase secretion which are actually responsible for the conversion of bound $\mathrm{P}$ into available form and hence lesser P-uptake in high superphosphate concentration (Prasad et al., 2012).

\section{Plant phosphorus content and Plant Nitrogen content}

The amount of plant phosphorus significantly increased $(p>0.001, \mathrm{~F}=12.133)$ in inoculated plantlets at low level of phosphorus as compared to the control plantlets after 90 days of inoculation. At this level, highest plant $\mathrm{P}$ content was found in the plantlets inoculated with AM fungi G. aggrgatum $(0.0284 \mathrm{gm} / \mathrm{kg}$ $\pm 0.0004)$. In the medium concentration, there was no significant difference between the results of plant phosphorus contents among the mycorrhizal and non-mycorrhizal plants. 
Table.1 Shoot length, root length, of $P$. mullesua plants after inoculation with AM fungi at Pfertilizer level - I, II and III (P-I, P-II, P-III)

\begin{tabular}{|c|c|c|c|c|c|c|}
\hline \multirow{2}{*}{$\begin{array}{l}\text { Mycorrhizal } \\
\text { isolates }\end{array}$} & \multicolumn{2}{|c|}{ Shoot Length } & & & \multicolumn{2}{|c|}{ Root Length } \\
\hline & & $(\mathrm{cm})$ & & & $(\mathrm{cm})$ & \\
\hline & P-I & P-II & P-III & P-I & P-II & P-III \\
\hline \multirow[t]{2}{*}{ Control } & 5.67 & 8.25 & 8.22 & 42.83 & 46.17 & 46.83 \\
\hline & \pm 0.25 & \pm 0.12 & \pm 0.09 & \pm 0.10 & \pm 0.82 & \pm 2.36 \\
\hline \multirow[t]{2}{*}{ G. etinucatum } & 8.5 & 7.77 & 5.43 & 33.33 & 34.73 & 42 \\
\hline & \pm 0.33 & \pm 0.13 & \pm 0.13 & \pm 0.51 & \pm 0.52 & \pm 0.95 \\
\hline \multirow[t]{2}{*}{ G. versiforme } & 8.33 & 7.1 & 5.67 & 32.67 & 39.67 & 43.67 \\
\hline & \pm 0.25 & \pm 0.12 & \pm 0.25 & \pm 0.10 & \pm 1.02 & \pm 0.10 \\
\hline \multirow[t]{2}{*}{ G. albidum } & 6.5 & 6.2 & 5.1 & 39.5 & 41 & 44.33 \\
\hline & \pm 0.17 & \pm 0.12 & \pm 0.32 & \pm 0.50 & \pm 0.76 & \pm 0.19 \\
\hline \multirow[t]{2}{*}{ G. claroidium } & 8.83 & 7.33 & 6.17 & 33.5 & 35.17 & 45.17 \\
\hline & \pm 0.35 & \pm 0.25 & \pm 0.42 & \pm 0.29 & \pm 0.75 & \pm 0.25 \\
\hline \multirow[t]{2}{*}{ G. occultum } & 6.17 & 6.15 & 5.33 & 39.17 & 40.9 & 43.33 \\
\hline & \pm 0.10 & \pm 0.19 & \pm 0.14 & \pm 0.92 & \pm 1.18 & \pm 0.25 \\
\hline \multirow[t]{2}{*}{ G. macrocarpum } & 7.67 & 6.6 & 5.23 & 40.67 & 39 & 44 \\
\hline & \pm 0.38 & \pm 0.06 & \pm 0.13 & \pm 0.48 & \pm 1.36 & \pm 0.17 \\
\hline \multirow[t]{2}{*}{ G. hoi } & 7.17 & 6.13 & 5.33 & 40.33 & 41.27 & 42.67 \\
\hline & \pm 0.25 & \pm 0.20 & \pm 0.25 & \pm 0.54 & \pm 0.85 & \pm 0.10 \\
\hline \multirow[t]{2}{*}{ G. aggregatum } & 7.5 & 6.37 & 5.37 & 36.02 & 34 & 43.17 \\
\hline & \pm 0.29 & \pm 0.17 & \pm 0.11 & \pm 0.73 & \pm 0.33 & \pm 0.10 \\
\hline \multirow[t]{2}{*}{ G. fasciculatum } & 6.5 & 5.77 & 5.17 & 36.03 & 38.33 & 42.83 \\
\hline & \pm 0.33 & \pm 0.08 & \pm 0.42 & \pm 0.45 & \pm 0.35 & \pm 0.25 \\
\hline \multirow[t]{2}{*}{ G. aurantium } & 6.33 & 6 & 5 & 36.97 & 39 & 42.5 \\
\hline & \pm 0.10 & \pm 0.17 & \pm 0.29 & \pm 0.62 & \pm 0.60 & \pm 0.17 \\
\hline
\end{tabular}


Table.2 Chlorophyll, infection and survivility of $P$. mullesua plants after inoculation with AM fungi at P-fertilizer level - I, II and III (P-I, P-II, P-III)

\begin{tabular}{|c|c|c|c|c|c|c|c|c|c|}
\hline Mycorrhizal & & orophyll & & & ction & & Su & ivality & \\
\hline isolates & & (mg) & & & $\%$ & & & $\%$ & \\
\hline & P-I & P-II & P-III & P-I & P-II & P-III & P-I & P-II & P-III \\
\hline Control & 1.603 & 1.727 & 1.738 & - & - & - & 40 & 80 & 70 \\
\hline & \pm 0.028 & \pm 0.015 & \pm 0.002 & & & & & & \\
\hline G. etinucatum & 1.76 & 1.747 & 1.721 & 50 & 33.33 & 10 & 60 & 60 & 40 \\
\hline & \pm 0.034 & \pm 0.008 & \pm 0.005 & \pm 3.33 & \pm 1.92 & \pm 5.8 & & & \\
\hline G. versiforme & 1.717 & 1.745 & 1.693 & 53.33 & 33.33 & 20 & 70 & 50 & 40 \\
\hline & \pm 0.026 & \pm 0.004 & \pm 0.009 & \pm 3.85 & \pm 5.09 & \pm 3.3 & & & \\
\hline G. albidum & 1.764 & 1.715 & 1.699 & 56.67 & 43.33 & 16.7 & 80 & 60 & 50 \\
\hline & \pm 0.024 & \pm 0.003 & \pm 0.014 & \pm 1.92 & \pm 3.85 & \pm 5.1 & & & \\
\hline G. claroidium & 1.902 & 1.768 & 1.705 & 70 & 36.67 & 8.3 & 90 & 60 & 60 \\
\hline & \pm 0.020 & \pm 0.006 & \pm 0.011 & \pm 3.33 & \pm 1.92 & \pm 2.5 & & & \\
\hline G. occultum & 1.861 & 1.732 & 1.68 & 46.67 & 23.33 & 6.7 & 60 & 50 & 60 \\
\hline & \pm 0.025 & \pm 0.006 & \pm 0.006 & \pm 1.92 & \pm 1.92 & \pm 2.5 & & & \\
\hline G. macrocarpum & 1.802 & 1.744 & 1.699 & 73.33 & 36.67 & 18.3 & 80 & 40 & 40 \\
\hline & \pm 0.009 & \pm 0.009 & \pm 0.007 & \pm 6.94 & \pm 5.09 & \pm 4.2 & & & \\
\hline G. hoi & 1.753 & 1.708 & 1.667 & 66.67 & 33.33 & 15 & 60 & 70 & 40 \\
\hline & \pm 0.020 & \pm 0.011 & \pm 0.004 & \pm 1.92 & \pm 1.92 & \pm 1.7 & & & \\
\hline G. aggregatum & 1.724 & 1.737 & 1.659 & 43.33 & 26.67 & 11.7 & 80 & 50 & 55 \\
\hline & \pm 0.007 & \pm 0.010 & \pm 0.011 & \pm 1.92 & \pm 3.85 & \pm 2.5 & & & \\
\hline G. fasciculatum & 1.722 & 1.718 & 1.633 & 60 & 40 & 13.3 & 70 & 50 & 40 \\
\hline & \pm 0.017 & \pm 0.006 & \pm 0.007 & \pm 3.33 & \pm 3.33 & \pm 1.0 & & & \\
\hline G. aurantium & 1.733 & 1.724 & 1.637 & 66.67 & 26.67 & 6.7 & 60 & 60 & 40 \\
\hline & \pm 0.040 & \pm .002 & \pm 0.004 & \pm 1.92 & \pm 1.92 & \pm 1.9 & & & \\
\hline$\pm \mathrm{SE}, \mathrm{n}=3$ & & & & & & & & & \\
\hline
\end{tabular}


Table.3 Correlation coefficient between Biomass and Percentage infection, Phosphatase content, Phosphorus and Plant Nitrogen in P mullesua seedling grown in Phosphorus level I, II and III

P-Level Infection Phosphatase Phosphorus Nitrogen

$\begin{array}{cllll}\text { P-I } & -0.295^{*} & 0.816 & 0.652 & 0.712 \\ & \text { ns } & p>0.001 & p>0.05 & p>0.005 \\ & & & & \\ \text { P-II } & 0.107^{*} & 0.765 & 0.780 & 0.609 \\ & \text { ns } & p>0.005 & p>0.005 & p>0.05 \\ & & & & \\ \text { P-III } & 0.233^{*} & 0.731 & 0.585 & 0.448 \\ & \text { ns } & p>0.005 & p>0.05 & \mathrm{~ns} \\ * d f=9, d f=10, \text { ns= Not significant } & & & \end{array}$

Figure.1 Total Biomass (gm) produced by $P$. mullesua seedlings infected with different mycorrhizal isolates and non-mycorrhizal one in phosphorus level $\mathbf{P}$ P-I, $\square$ P-II and $\square$ P-III

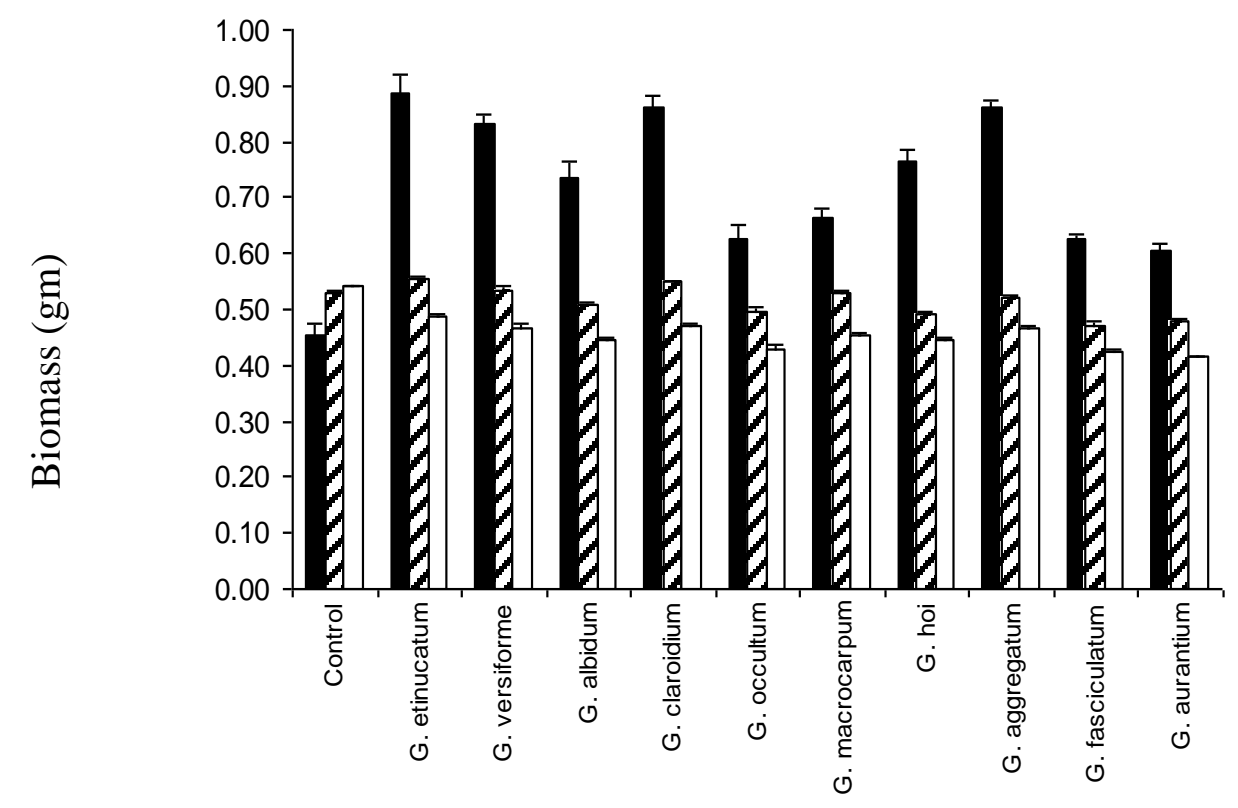

Mycorrhizal isolates 
Figure.2 Total Phosphatase $(\mu \mathrm{gm} / \mathrm{gm})$ produced by P. mullesua seedlings infected with different mycorrhizal isolates and non-mycorrhizal one in phosphorus level $\mathbf{\square}$ P-I, $\square$ P-II and $\square$

$$
\text { P-III }
$$

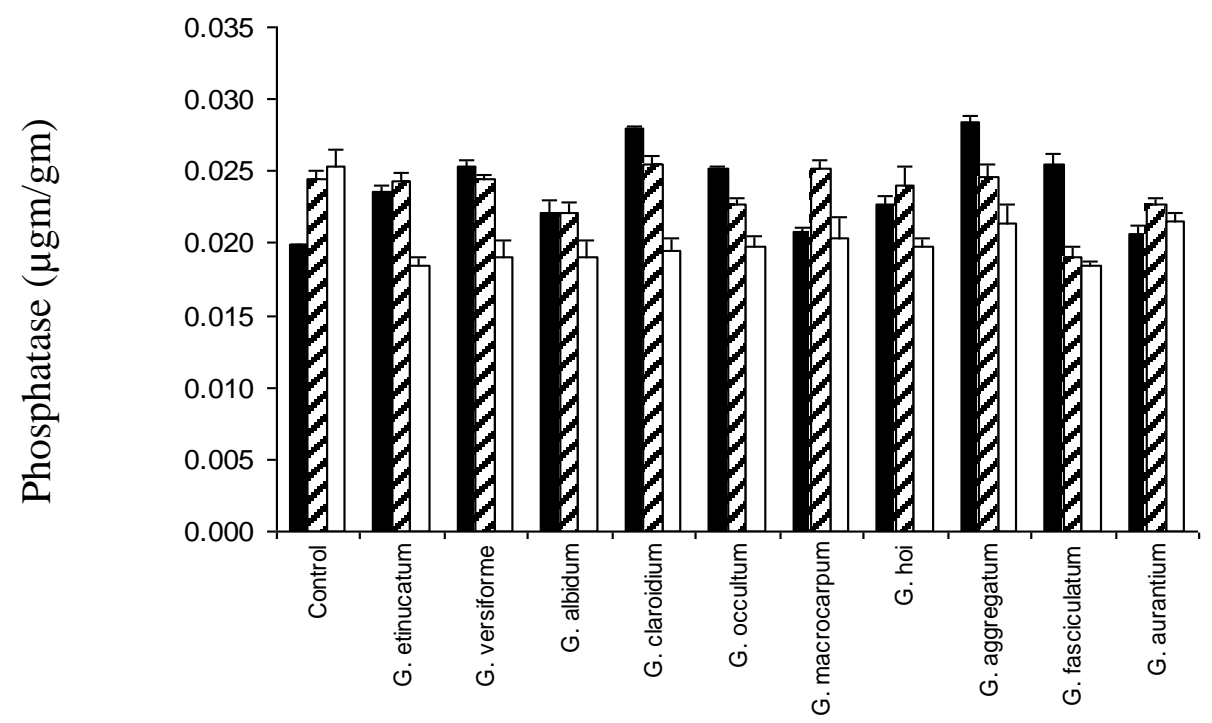

Mycorrhizal isolates

Figure.3 Total Phosphorus $(\mathrm{gm} / \mathrm{km})$ produced by P. mullesua seedlings infected with different mycorrhizal isolates and non-mycorrhizal one in phosphorus level $\square$ P-I, $\square$ P-II and $\square$ P-III

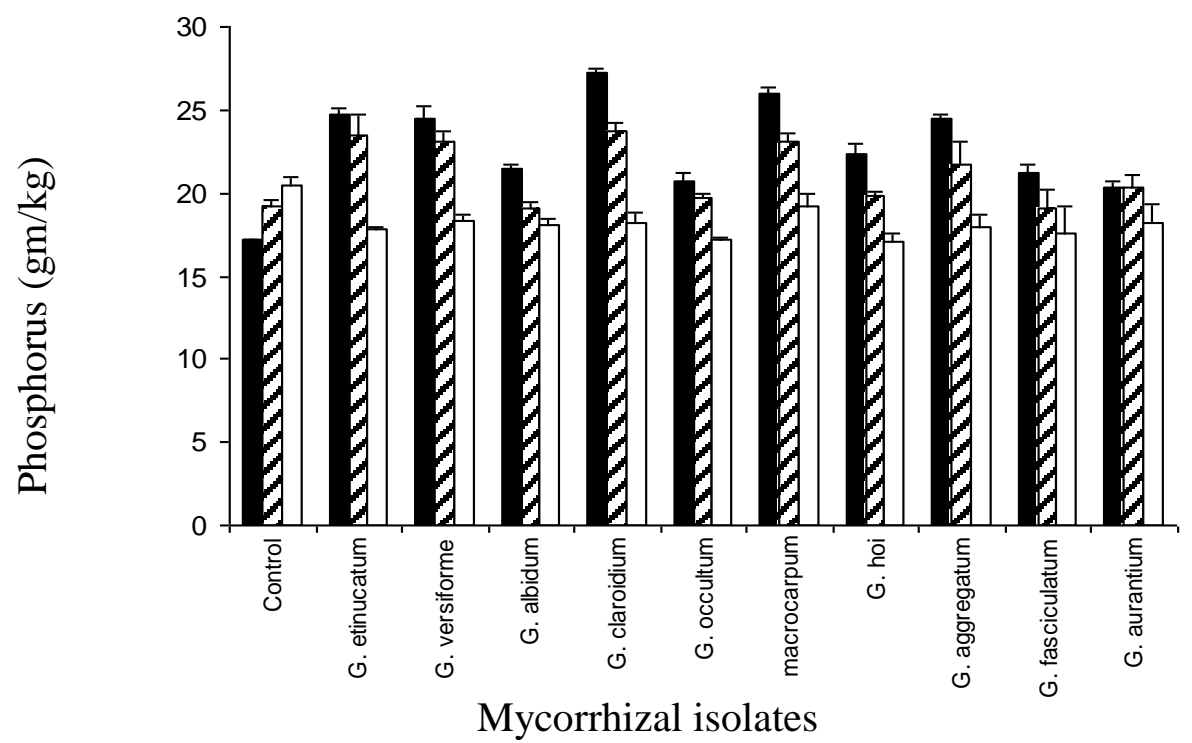


Figure.4 Total Nitrogen (\%) produced by $P$. mullesua seedlings infected with different mycorrhizal isolates and non-mycorrhizal one in phosphorus level $\square$ P-I, $\square$ P-II and $\square$ P-III

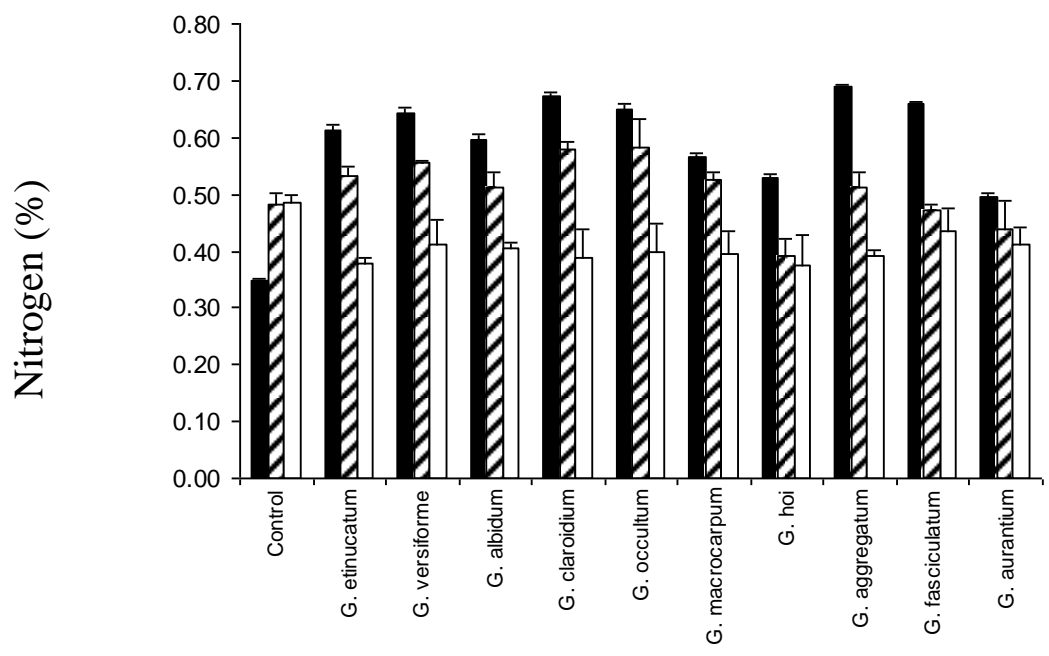

Mycorrhizal isolates

Highest plant phosphorus content was found in the plantlets inoculated with $G$. macrocarpum $(0.025 \mathrm{gm} / \mathrm{kg} \quad \pm 0.0007)$ and least was found in $G$. fasciculatum $(0.019 \mathrm{gm} / \mathrm{kg} \pm 0.0007)$, whereas $\mathrm{P}$ content of non-mycorrhizal control plant was $0.024 \mathrm{gm} / \mathrm{kg} \pm 0.0006$. At higher level of $\mathrm{P}$, plant phosphorus content was significantly less than the non-mycorrhizal control plants $(0.0254 \mathrm{gm} / \mathrm{kg} \pm 0.0012)$ whereas AM fungi inoculated plants were ranged $0.0214 \mathrm{gm} / \mathrm{kg}$ \pm 0.0013 to $0.0184 \mathrm{gm} / \mathrm{kg} \pm 0.0005$ (Figure 3 ).

In case of low level P, significantly ( $p>0.001$, $\mathrm{F}=27.133$ ) higher Nitrogen was found in the plantlets inoculated with $G$. aggregatum $(0.69 \% \pm 0.003)$ and least was found in $G$. aurantium $(0.5 \% \quad \pm 0.007)$. Plant Nitrogen content was found in non-mycorrhizal control plant was found $0.35 \% \pm 0.005$. At medium $P$ level, plant Nitrogen was found highest in the seedlings inoculated with $G$. occulatum $(0.58 \% \pm 0.049)$ and least was found in G. hoi $(0.39 \% \pm 0.033)$. Nitrogen content was recorded $0.48 \% \pm 0.019$ in the non- mycorrhizal seedlings. Non-mycorrhizal control plants produced highest nitrogen content in shoots $(0.48 \% \pm 0.012)$ compared to the AM inoculated plants ranged $0.43 \%$ \pm 0.039 to $0.38 \% \pm 0.019$ at higher level of $\mathrm{P}$ (Figure 4). In medium and higher level of $\mathrm{P}$, there was no significant increase in plant Nitrogen.

Plant phosphorus and Plant Nitrogen content was found higher in the experiment containing low level of superphosphate, where half of recommended dose of superphosphate was used. Same results was reported by George (2000) and suggested that on soils deficient in $\mathrm{P}$, mycorrhizal colonization supports plant development by supplying the plant with additional $\mathrm{P}$ and sometimes with $\mathrm{N}, \mathrm{K}$ or Zn. Tanwar et al., (2013) also supported that Mycorrhizal inoculation alone did not significantly influence the concentration of plant phosphorus and total nitrogen $(\mathrm{N})$. AM fungi and $\mathrm{P}$ fertilizer together resulted in significant increase in the concentration of both 
phosphorus and nitrogen compared to their respective control but higher $\mathrm{P}$ application doesn't support the increment in plant nutrient level. These results are in accordance with the findings of Rakshit and Bhadoria (2009) that highest phosphorus uptake occurs in mycorrhizal maize plants with added low $\mathrm{P}$ than non-mycorrhizal as well as plants without added $P$. Increase in $P$ and $N$ in plantlets at low level superphosphate might be due to the ability of the mycorrhizal fungi to extrametrical hyphae in the roots and ultimately help for absorption of water, available phosphorus and other nutrients for plant growth. Findings of Gosling et al., (2005) and Tiamtanong et al., (2015) supported our results. Although we found low $\mathrm{P}$ and $\mathrm{N}$ concentration in shoot tissues of higher $\mathrm{P}$ level. This may be due to less mycorrhizal infection at higher soil $\mathrm{P}$ level which showed similar result with Perner et al., (2007). In our experiments, plantlets inoculated with few mycorrhizal fungi showed less plant phosphorus than the control plants. This might be the fact that phosphorus and nitrogen uptake in mycorrhizal plants through Mycorrhizal pathway can reduce Direct pathway of nutrient acquisition resulting reduced mineral nutrients in mycorrhizal plantlets as compared to the control plants containing only direct pathway of nutrient uptake (Nouri et al., 2014).

In our experiment, the correlation coefficient of plant biomass with phosphatase $(p>0.001$, $p>0.005, p>0.005)$ and phosphorus $(p>0.05$, $p>0.005, p>0.05)$ was found significantly positive with respect to the levels of phosphorus concentration. But at higher concentration of $\mathrm{P}$ nitrogen content, biomass was found non significant in relation to nitrogen content of the plantlets. Biomass was found non significant in relation to the infection at all the levels of $\mathrm{P}$ in Piper mullesua plantlets.

\section{References}

Aliyu, I.A., Yusuf, A. A., Uyovbisere, E.O., Masso, C. and Sanders, I.R. (2019). Effect of co-application of phosphorus fertilizer and in vitro-produced mycorrhizal fungal inoculants on yield and leaf nutrient concentration of cassava. PLoS ONE 14(6): e0218969. https://doi.org/10.1371/journal.

pone.0218969

Allen, M..F., Smith, W.K., Moore, T.S., Christensen, M. (1981). Comparative water relations and photosynthesis of mycorrhizal Bouteluoa gracilis. New Phytologist. 88: 683-693

Azcon-Aguilar, C and Barea, J.M. (1997). Applying mycorrhiza biotechnology to horticulture: significance and potentials. Scientific Horticulture 68: 1-24.

Azcón, R., and Barea, J. M. (1997b). Mycorrhizal dependency of a representative plant species in Mediterranean shrublands (Lavandula spica L.) as a key factor to its use for revegetation strategies in desertification threatened areas. Applied Soil Ecology 7 , http://dx.doi.org/10.1016/S09291393(97)00013-9

Balzergue, C., Chabaud, M., Barker, D.G., Bécard, G. and Rochange, S.F. (2013). High phosphate reduces host ability to develop arbuscular mycorrhizal symbiosis without affecting root calcium spiking response to the fungus. Frontiers in Plant Science 4: 1-15

Brachmann, A., and Parniske, M. (2006). The most widespread symbiosis on earth. PLoSBiol. 4:e239. doi: 10.1371/journal.pbio.0040239

Brinch-Pedersen, H., Sorensen, L.D. and Holm, P.B. (2002). Engineering crop plants: Getting a handle on phosphate. Trends in plant Science 7(3): 118-125 
Brundrett, M., Bougher, N., Dell, B., Grove, T. and Malajczuk, N. (1996). Working with mycorrhizas in forestry and agriculture. ACIAR monograph 32. Australian Centre for International Agricultural Research. Canberra: 184193

Bucher, M. (2006). Functional biology of plant phosphate uptake at root and mycorrhiza interfaces. New Phytologist 173(1): 11-26

Cavagnaro, T.R. (2008). The role of arbuscular mycorrhzas in improving plant zinc nutrition under low soil zinc concentrations: a review. Plant and Soil 304: 315-325.

Ceballos, I., Ruiz, M., Fernandez, C., Pena, R., Rodriguez, A. and Sanders, I.R. (2013). The in vitro mass-prodcued model mycorrhizal fungus, Rhizophagus irregularis, significantly increases yields of the globally important food security crop cassava. PLOS One 8(8): 1-10.

Cordell, D., Drangert, J.O., and White, S.(2009).The story of phosphorus: global food security and food forthought. Global Environmental Change 19, 292-305.doi: 10.1016/ j.gloenvcha. 2008.10.009

Cooper, K.M. (1984). Physiology of VAM associations. In: Powell, C.L., Bagyaraj, D.J. (Eds) VA Mycorrhiza, CRC Press Inc., Boca Raton, Florida, pp: 155-186.

El-Khateeb, M.A., El-Madawy, E., El-Attar, A. (2010). Effect of some biofertilizers on growth and chemical composition of Chamaedorea elegans Mart Seedlings. Journal of Horticultural Science and Ornamental Plant. 2: 123-129.

Gaur, A., Gaur, A., Adholeya, A. (2000). Growth and flowering in Petunia hybrida, Callistephus chinensis and Impatiens balsamina inoculated with mixed AM inocula or chemical fertilizers in a soil of low $\mathrm{P}$ fertility.
Scientia Horticulture. 84: 151-162.

Gerdmann, J.W. and Nicholson, T.H. (1963). Spores of mycorrhizal endogone species extracted from soil by wet sieving and decanting. Transactions of the British Mycological Society. 46: 235-244.

George E (2000) "Nutrient uptakeContributions of arbuscular mycorrhizal fungi to plant mineral nutrition," in Arbuscular Mycorrhizas: Physiology and Functions, eds Y. Kapulnik and D.D. Douds (Dordrecht: Kluwer Academic Publishers): 307-343

Gilbert, N.(2009).The disappearing nutrient. Nature 461, 716-718.doi: 10.1038/461716a

Gosling, P., Higge, A., Goodlass, G., and Bending, G. D. (2005). Arbuscular mycorrhizal fungi and organic farming. Agricultural Ecosystem and Environment 133: 17-35.

Guillemin, J.P., Orazco, M.O., GianinazziPearson, V., Gianinazzi, S. (1995). Influence of phosphate fertilization on fungal alkaline phosphatase and succinate dehydrogenase activities in arbuscular mycorrhizal of soybean and pineapple. Agriculture Ecosystem and Environment 53: 63-69.

Harrison, M.J.,and van Buuren, M. L. (1995). A phosphate transporter from the mycorrhizal fungus Glomus versiforme. Nature 378: 626-629. doi: $10.1038 / 378626 a 0$

Juo, A. S. R. (1982). Automated and semi automated methods for soil and plant analysis manual series, No 7. Published and printed by International Institute of Tropical Agriculture (IITA), Ibadan, Nigeria: 33

Kumar, D., Hussain, R., Rahul., Aarti. and Kumar, A. (2019). Development of Mycorrhiza and their Influence on Nutrient Status, Plant Growth and Innate Immunity. International .Journal of Current .Microbiology and .Applied 
Science 8(12): 1886-1891. doi: https://doi.org/10.20546/ijcmas.2019.81 2.225

Linderman, R. G. and Davis, E. A. (2004). Evaluation of commercial inorganic and organic fertilizer effect on arbuscular mycorrhizae formed by Glomus intraradices. Horticultural Technology 14: 196-202.

Mengel, K and Kirkby F.A. (2001). Principals of plant nutrition. Dordrecht, the Netherlands: Kluwer Academic Publishers.

Nouri, E., Breuillinsessoms, F., Feller, U., and Reinhardt, D. (2015). Phosphorus and nitrogen regulate arbuscular mycorrhizal symbiosis in Petunia hybrid. PLoS One 9, e90-841. doi: 10.1371/journal.pone.0127472

Ohtomo, R. and Saito, M. (2005). Polyphosphate dynamics in mycorrhizal roots during colonization of an arbuscular mycorrhizal fungus. New Phytologist 167: 571-578.doi: 10.1111/j.1469-8137.2005.01425.x

Prasad, K., Aggarwal, A., Yadav, K. and Tanwar, A. (2012). Impact of different levels of superphosphate using arbuscular mycorrhizal fungi and Pseudomonas fluorescens on Chrysanthemum indicum L. Journal of Soil Science and Plant Nutrition, 12 (3): 451-462

Perner, H., Schwarz, D., Bruns, C., Mader, P. and George, E. (2007). Affect of arbuscular mycorrhizal colonization and two levels of composts supply on nutrient uptake and flowering of Pelargonium plants. Mycorrhiza. 17: 469-474.

Rakshit, A. and Bhadoria, P.S. (2009). Role of VAM on growth and phosphorus nutrition of maize with low soluble phosphate fertilization. Acta Agronomy 59(1): 119-123.

Raghothama, K.G. (1999). Phosphatase acquisition. Annals Review of Plant Physiology and Plant Molecular Biology. 50: 665-693.

Schachtman, D.P., Reid, R.J. and Ayling, S.M. (1998). Phosphorus uptake by plants: From soil to cell. Plant physiology. 116: 447-453.

Singh, A., Singh, D. and Singh, N. (2019). Growth and Yield Response of Mungbean Plants to Colonization of Arbuscular Mycorrhizal Fungi (AMF) (Glomus macrocarpon) and Phosphorus Amendments. International .Journal of Current .Microbiology and .Applied .Science 8(12): 3039-3048. doi: https://doi.org/10.20546/ijcmas.2019.81 2.354

Smith, S.E. and Read, D.J. (1997). Mycorrhizal symbiosis. 2nd Ed. Academic Press, London.

Smith, S.E. and Read, D.J.( 2008). Mycorrhizal symbiosis. Elsevier, New York, NY

Srivastva, S., Gupta, M.M., Verma, R.K. and Kumar, S. (2001). Determination of 1,3Benzodioxanes in Piper mullesua by High-Performance Thin-Layer Chromatography. Pharmaceutical Biology. 83(6): 1484-1488.

Subramanian, K.S., Bharathi, C. and Jegan, A. (2008). Response of maize to mycorrhizal colonization at varying levels of zinc and phosphorus. Biology and Fertility of Soils 45:133-144

Tabatabai, M.A. and Bremner, J.M. (1969). Use of p-nitrophenylphosphate for assay of soil phosphatase activity. Soil Biology and Biochemistry 1:301-307

Tadano, T., Ozawa, K., Sakai, H., Osaki, M., and Mutsui, H. (1993). Secretion of acid phosphatase by the roots of crop plants under phosphorus deficient conditions and some properties of the enzyme secreted by lupin roots. Plant and Soil. 155:

95-98. http://dx.doi.org/10.1007/BF00024992 
Tanwar, A., Aggarwal, A., Kadian. N. and Gupta, A. (2013). Arbuscular mycorrhizal inoculation and super phosphate application influence plant growth and yield of Capsicum annuum. Journal of Soil Science and Plant Nutrition 13(1): 55-66

Tiamtanong, S., Sinma, K., Mala, T., Rungcharoenthong, P. and Amkha, S. (2015). Effects of Mycorrhizal Fungi with Phosphate Fertilizer Applications on Phosphate Solubilizing and Soil Properties of Grapes Orchard. Modern Applied Science. 9(1):149-156

Witham, F.H., Blaydes, D.F. and Devlin, R.M. (1971). Experiments in Plant physiology. Van Nostrend Reinhold
Company, New York

Zafar, M., Abbasil, M.K., Rahim, N., Khaliq, A., Shaheen, A. and Jamil, M. (2011). Influence of integrated phosphorus supply and plant growth promoting rhizobacteria on growth, nodulation, yield and nutrient uptake in Phaseolus vulgaris. African Journal of Biotechnology 10(74): 16793-16807.

Zhang, F., Wang, P. and Zou, Y.N. (2019). Effects of mycorrhizal fungi on roothair growth and hormone levels of taproot and lateral roots in trifoliate orange under drought stress. Archives of Agronomy and Soil Science 65(9): 1316-1330

\section{How to cite this article:}

Arundhati Bordoloi and Shukla, A. K. 2020. Efficiency of Mycorrhizal Fungi with Different Levels of Phosphatic Fertilizer on Growth of Piper mullesua Plantlets. Int.J.Curr.Microbiol.App.Sci. 9(03): 771-785 doi: https://doi.org/10.20546/ijcmas.2020.903.092 